\title{
3D Yazıcı ile Yazdırılmış Malzemede Ahşap Kaplama Laminasyonunun Eğilme Direncine Etkisi
}

\author{
Yasemin ÖZTÜRK ${ }^{1 *}$, Erol BURDURLU ${ }^{1}$ \\ ${ }^{1}$ Gazi Üniversitesi, Teknoloji Fakültesi, Ağaçişleri Endüstri Mühendisliği Bölümü, 06500, ANKARA
}

Öz

Üretim sistemlerinde önemli değişimlere neden olacak 3D yazıcı teknolojileri, ortaya çıkan yeni gelişmeler ve düşen maliyetlerle, malzeme ve sonuç ürün üretimi odaklı olarak üzerinde en çok AR-GE faaliyeti yürütülen alanlardan biri haline gelmiştir. Bu çalışmada, ahşap katkılı filament ile 3D yazıcıda üretilmiş malzemenin, ahşap kaplamalarla laminasyonunun eğilme direncine etkisinin belirlenmesi amaçlanmıştır. Bu amaçla 3D yazıcıda ahşap katkılı filament kullanılarak, \% 50'lik doluluk oranı ile 10 x 10 x 180 mm boyutlarında 18 adet ara katman parçası yazdırılmış ve bu parçalar ıhlamur ve kayın kaplamalar ile lamine edilmiştir. Yazıcıdan alınmış her bir malzeme kontrol grubu, kayın kaplama ve ihlamur kaplama ile lamine edilecekler olmak üzere 3 gruba ayrılmış ve her malzemenin alt ve üst kısmına 0,5 mm kalınlığında olan bu kaplamalar PVAc tutkalı kullanılarak yapıştırılmıştır. Elde edilen lamine malzemeler üniversal test cihazında eğilme testine tabi tutulmuştur. Test sonucunun SPSS 22 programında yapılan istatistiksel değerlendirmesi sonucunda, laminasyon işleminin, eğilme direncini kayın kaplama ile \%25 ve ıhlamur kaplama ile \%20 arttırdığı, kayın kaplama ile lamine edilmiş malzemelerin eğilme dayanımının en yüksek (46,41 MPa) olduğu belirlenmiştir.

Anahtar Kelimeler: 3D malzemeler, laminasyon, ahşap katkılı filament, eğilme direnci.

\section{The Effect of Wood Veneer Lamination on the Flexural Strength of the Material Produced with 3D- Printed Material}

\begin{abstract}
3D printer technologies, which will cause radical changes in production systems, have become one of the fields on which the most R\&D activities are carried out, with a focus on material and end product production, with new developments and falling costs. This study aimed to determine the effect of lamination of wood-added filament and 3D-printed material with wood veneers on bending resistance. For this purpose, 18 interlayer pieces in $10 \mathrm{x}$ $10 \times 180 \mathrm{~mm}$ sizes were printed using wood-added filament in 3D printer, with 50\% fill rate, and these pieces were laminated with linden and beech veneers. Each control group of material taken from the printer was divided into 3 groups, those to be laminated with beech veneer and those to be laminated with linden veneer, and these coatings of $0.5 \mathrm{~mm}$ thickness were adhered to the top and bottom of each material using PVAc glue. The laminated materials obtained were subjected to bending test in a universal testing device. As a result of the statistical evaluation of the test result in the SPSS 22 program, it was determined that the lamination process increased the bending strength of the material by $25 \%$ with beech veneer and by $20 \%$ with linden veneer and it was determined that the flexural strength of the materials laminated with beech veneer was the highest (46.41 MPa).
\end{abstract}

Keywords: 3D materials, lamination, wood-reinforced filament, bending strength. 


\section{Giriş}

Hız, günümüz dünyasının en önemli unsurlarının başında gelmektedir. Hayatın olağan akışı da dahil olmak üzere bireyler ve firmalar bu hıza ayak uydurmaya çalışmaktadır. Hayat döngüsü içerisinde devamlılı̆ı̆ın sağlanması için üretmek önemli bir yer tutarken, üretiminde mevcut hıza ayak uydurmuş olması gerekmektedir. Üretim sektörü açısından incelendiğinde, özellikle ürünlerin prototiplerinin üretilme aşamalarının en az miktarda atık çıkartarak, en hızlı ve en ekonomik şekilde çözümlenebilmesi amacıyla son dönemlerde 3 boyutlu yazıcılar siklıkla kullanılmaktadır.

3 boyutlu yazıcılarda genellikle, petrol türevi olan Akrilonitril Bütadien Stiren (ABS) ve şeker kamışı, mısır gibi nişasta içeren ürünlerden elde edilen Polilaktik Asit (PLA) kullanılmaktadır. Kullanım oranına bakıldığında ise çevre dostu olan PLA filamentlerin kullanımının daha fazla olduğu görülmektedir (Aydın ve Kahraman 2018). 3 boyutlu yazıcılardan en fazla sağlık sektöründe yararlanılıyor olsa da mobilya sektörü de 3 boyutlu yazıcıların kullanımının arttığı sektörlerden birisidir ki bunun en önemli sebeplerinden birisi gelişen teknolojidir.

Mobilya sektöründe 3 boyutlu yazıcı kullanımının artışına bağlı olarak bilim insanları ve uygulayıcılar 2 farklı alanda gelişimlere katkı sağlamak için çalışmalar yapmaktadır. Bunlardan ilki kullanılan PLA filamentlerin içerisine ahşap katkılar ve bitkisel lif eklenmesi ile filamentlerin ahşap görünümünü ve mekanik özelliklerinin arttırılması, ikincisi ise bağlantı elemanları, mobilya parçaları ve mobilya ayakları gibi aksesurların üretiminin bu yöntemle yapılmasıdır (Yıldırımı ve Kahraman 2019; Gedik vd. 2018; Yıldırım vd. 2019). Yapılan çalışmalarda ürüne eklenen bitkisel kaynakların her ne kadar PLA'nın mekanik özellikleri üzerinde olumsuz etkileri olabildiği görülse de bu etkilerin giderilmesi için uygulama yöntemleri ve kullanılan malzemeler için geliştirme çalışmaları devam etmektedir (Zondi vd. 2020; Chansoda vd. 2020; Bhagia vd. 2020). Ayrıca mobilya elemanlarının boyutlarının büyük olması sebebiyle de tamamının üretimini yapmak her zaman mümkün olamamaktadır.

Ahşap katkılı PLA filamentler ile üretilen ürünlerde ahşap görüntüsü elde edilebilmekle birlikte elastiklik modülü değeri düşmektedir. Gerilme mukavemeti açısından ahşap katkı1ı PLA filament ile silan takviyeli ahşap unu ile üretilen PLA filament arasında bir fark görülmezken mPLA'nın gerilme mukavemeti saf PLA'nın değerinden \% 21 daha düşüktür (Petchwattana vd. 2019; Liu vd. 2019). PLA esaslı ahşap-plastik kompozitlerin gerilme mukavemeti, modifiye fiber oranının artışı ile önce artmakta ve sonra azalmaktadır. Modifiye edilmiş fiber miktarı \% 15'e ulaştığında, kompozitin gerilme mukavemeti maksimum olmaktadır (Liu vd. 2019). Ahşap katkılı filamentler için yazdırma sıcaklığının $230{ }^{\circ} \mathrm{C}$ 'nin üzerine çıkmaması gerekmektedir. Bu sıcaklık üzerinde ahşap katkıdan kaynaklanan bozulmalar nedeniyle çekme direnci azalmaktadır (Guessasma vd. 2019). Ticari olarak üretilen ahşap katkılı PLA ve ABS gibi farklı yazdırma gereçleri arasında yapılan karşılaştırmada, ahşap katkı oranı $\% 40$ olan filamentin çekme direnci değeri diğer malzemelerden daha düşüktür (Grabowik vd. 2017). PLA filament üretiminde mikrofibril ilavesi mekanik özelliklerde önemli bir etki yapmamaktadır (Winter vd. 2018). $\% 10, \% 20$ ve $\% 30$ bambu odunu kullanılarak yapılan çalışmanın sonuçlarına göre ahşap miktarı arttıkça pürüzlülük ve filament renginin koyuluğu artmaktadır. En iyi çekme dayanımı, 7,12 MPa ile \%10 bambu katkı oranı ile sağlanmaktadır (Shin vd. 2018). PLA filamentlerde kauçuk ağacı odun unu katkı oranının yazdırılan malzemenin mekanik özelliklerine etkisinin araştırıldığı çalışmada maksimum katkı oranı \%10 olarak belirlenmiştir (Chansoda vd. 2020).

Ahşap katmanların birbirine yapıştırılarak uygulaması sonucu elde edilen yapısal levhalar olan lamine levhaların ilk kullanımı M.Ö. 4300 yıllarında Mezopotamyalılar tarafından gerçekleştirilmiştir (URL1 1989). Laminasyon sonucu elde edilen malzemenin, istenilen boyutta olması, geniş açıklıkları rahatça geçebilmesi, istenilen formda çalı̧̧maya imkân tanıması, boyutsal stabilizasyonunun aynı türdeki masif malzemeden daha iyi olması, farklı kalınlık ve renklerdeki ağaçların kullanılabilmesi sonucunda estetik görünüme sahip malzemeler elde edilebilmesi gibi avantajları mevcuttur. Tüm bu avantajlarının yanında, tutkallama işleminin ek bir maliyet yaratması, direnci yüksek ürünler için kullanılacak kalitedeki tutkalların maliyetinin yüksek olması ve büyük boyutlu kavisli elemanların taşınması sırasında güçlüklerle karşılaşılması gibi dezavantajları da mevcuttur (Keskin 2003).

Ekonomik yönden değeri olmayan ve mekanik özellikleri yapı malzemesi olarak kullanıma uygun olmayan ancak fazla miktarda bulunan ağaçları değerlendirmek amacıyla lameller arasına takviye malzemeler kullanılmaktadır. Cam elyaf kumaş, elyaf takviyeli plastik, takviyeli bambu kullanılan paneller de eğilme dirençlerinde artışlar olmuştur (Karaman ve Yıldırım 2019; Osmannezhad vd. 2013; Kaboli ve Clouston 2019). Laminasyonda kullanılan kaplama ve ya papellerin kalite sınıfları, kat organizasyonları, katmanların kalınlıkları direnç özellikleri üzerinde artışlar sağlamaktadır. Katmanlarda kullanılan kaplamaların ısıtılması eğilme direncinde azalmalara sebep olmaktadır (Burdurlu vd. 2007; Nguyen vd. 2019; Wang vd. 2019; He vd. 2020). 
Sürekli iyileştirme felsefesine dayalı AR-GE faaliyetleri ile 3D teknolojisi giderek daha hızlı gelişmekte, birçok sektörde klasik üretim teknolojisinin yerini almakta ve donanım olarak Endüstri 4.0 olarak adlandırılan üretim stratejisinin önemli bir bileşeni haline gelmiş bulunmaktadır. Bu değişim, ahşap ürünler sektöründe de, 3D teknolojisi ile malzeme ve ürün üretimine ilişkin çalışmaları zorunlu kılmaktadır.

3D yazdırma teknolojisi ile üretilen ürünlerin ürün yapısal özellikleri büyük oranda yazıcıda kullanılan filamentlerin yapısal özelliklerine ve yazıcı ile ilgili uygulama değişkenleri (sıcaklık, yazdırma hızı gibi) bağlı olmaktadır. Filamentin yapısal özellikleri ise, üretiminde kullanılan ABS, PLA, naylon ve reçine gibi ana malzemeler yanı sıra odun unu, metal tozları, doğal veya yapay lifler, su iticiler gibi katkı maddelerinin oranlarına bağlı bulunmaktadır. Literatür incelemesinden görüleceği üzere, bu değişkenlerin 3D teknolojisi ile üretilmiş malzemenin özelliklerine etkilerinin belirlenmesine ilişkin çok sayıda araştırma olmasına rağmen, bu malzemenin laminasyonuna ilişkin çalışmalar son derece sınırlıdır. Laminasyon, malzemelerin dayanım özelliklerini iyileştirmede kullanılan önemli tekniklerden biridir. Bu tekniğin 3D teknolojisi ile üretilen malzemelerin yapısal özelliklerinde önemli değişiklikler yapacağı düşünülmektedir.

Bu çalışmada, 3D teknolojisi ile ahşap katkılı filamentlerden üretilen malzemede ahşap kaplama laminasyonunun malzemenin eğilme direnci özelliklerine etkisinin belirlenmesi amaçlanmış olup, laminasyon boyutu ile çalışma farkl1lık göstermektedir.

\section{Materyal ve Metot}

\subsection{Materyal}

Bu çalışmada, lamine malzemenin ara katmanını oluşturmak üzere 3D yazıcı ve ESUN marka ahşap katkılı filament, alt-üst yüzey katmanları için $0,5 \mathrm{~mm}$ kalınlığında ıhlamur ve kayın kaplama ve bu kaplamaları yapıştırmak için de Apel marka polivinil asetat ( PVAc) tutkalı kullanılmıştır. Filament üreticileri, ahşap katkılı filament üretiminde kullandıkları odun unu yüzdesi, odun unu türü ve tanecik büyüklüğü gibi bilgileri ticari sır olarak saklamakta ve bu sebeple etiket üzerinde bu bilgilere yer vermemektedir.

\subsection{Metot}

Açık sistem 3 boyutlu yazıcı ile ahşap katkılı PLA filament kullanılarak $200{ }^{\circ} \mathrm{C}$ nozul sıcaklığı ve $70 \mathrm{~mm} / \mathrm{s}$ dökme hızı ile \% 50 doluluk oranında (doluluk oranı: birim hacimdeki yazdırılan yapısal madde miktarının birim hacme oranıdır.) $10 \times 10 \times 180 \mathrm{~mm}$ boyutlarında 18 adet yoğunluğu $0,65 \mathrm{gr} / \mathrm{cm}^{3}$ olan 3D malzeme üretilmiştir. Çalışmada daha az filament kullanarak daha kısa süre de üretim yapılması amacıyla doluluk oranı $\% 50$ olarak belirlenmiştir. $\mathrm{Bu}$ oran için yazıcı programı üzerinden yapılan modellemeye göre filament tasarrufu \% 47 iken zaman tasarrufu ise \%70'dir. Üretilen parçalar $20{ }^{\circ} \mathrm{C}$ sıcaklık ve \% 65 bağıl nem şartlarında iklimlendirme kabininde değişmez ağırlığa gelinceye kadar bekletilerek hava kurusu hale (\%12) getirilmiştir. Parçalar, üst ve alt kısımlarına ağaçişleri endüstrisinde en fazla kullanılan kaplama olan 0,5 mm kalınlığında kayın ve ihlamur kaplamalar PVAc tutkalı ile yapıştırılarak lamine edilmiş ve universal test cihazında TS EN $408+$ A1 'e uygun olarak eğilme direnci testlerine tabi tutulmuştur (TS EN 408, 2014). Deney örneklerinin \%50 doluluk oranında yazdırılmış olması sebebiyle pres yerine işkenceler yardımı ile manuel sıkma uygulanmıştır. Manuel sıkma esnasında işkencelerin her birinin aynı oranda sıkılmasına dikkat edilmiştir. Lamine malzemenin katmanları şekil 1'de ve şekil 2' de gösterilmiştir.

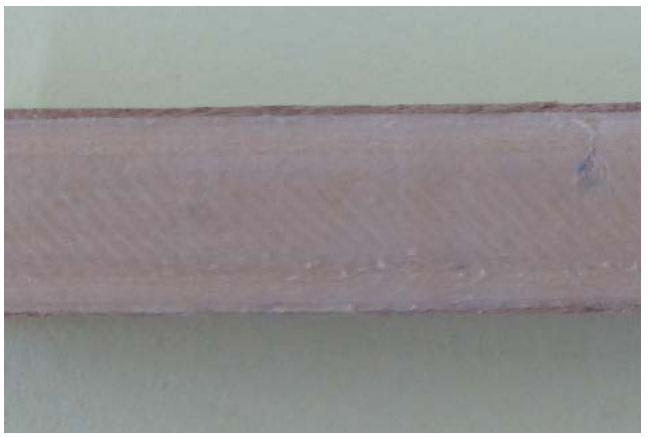

Şekil 1. Lamine malzeme

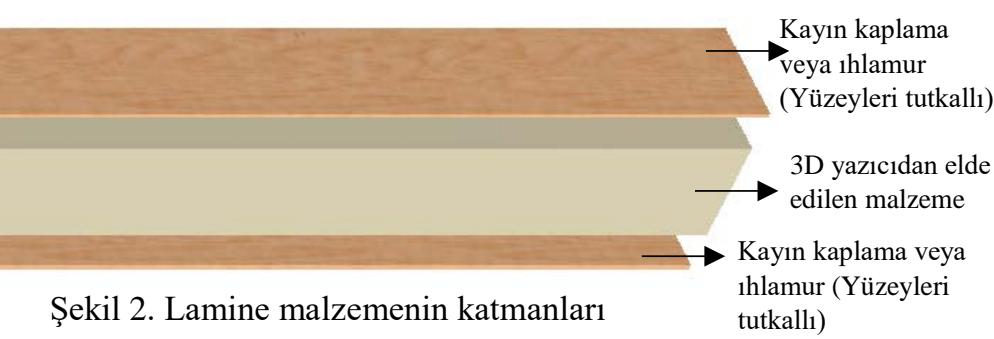

Şekil 2. Lamine malzemenin katmanları tutkallı) 
Numunelerin yazdırılmasında kullanılan 3D yazıcıya ait parametreler Tablo 1' de verilmiştir.

Tablo 1. Yazıcı parametreleri

\begin{tabular}{lc}
\hline & Yazıcıya Ait Parametreler \\
\hline Yazıcı Malzemesi & Ahşap Katkılı PLA \\
\hline Katman Yüksekliği (mm) & 0,3 \\
\hline Nozul çapı (mm) & 0,4 \\
\hline Doluluk Oranı (\%) & 50 \\
\hline Yazıcı Nozul sıcaklığı & $200^{\circ} \mathrm{C}$ \\
\hline Kabuk sayısı & 2 \\
\hline Filament Çapı (mm) & 1,75 \\
\hline Dolgu Örüntüsü & Doğrusal \\
\hline
\end{tabular}

Lamine edilmiş ağaç malzemelerin eğilme direnci testlerinin yapıldığı test düzeneği şekil 3' de verilmiştir.

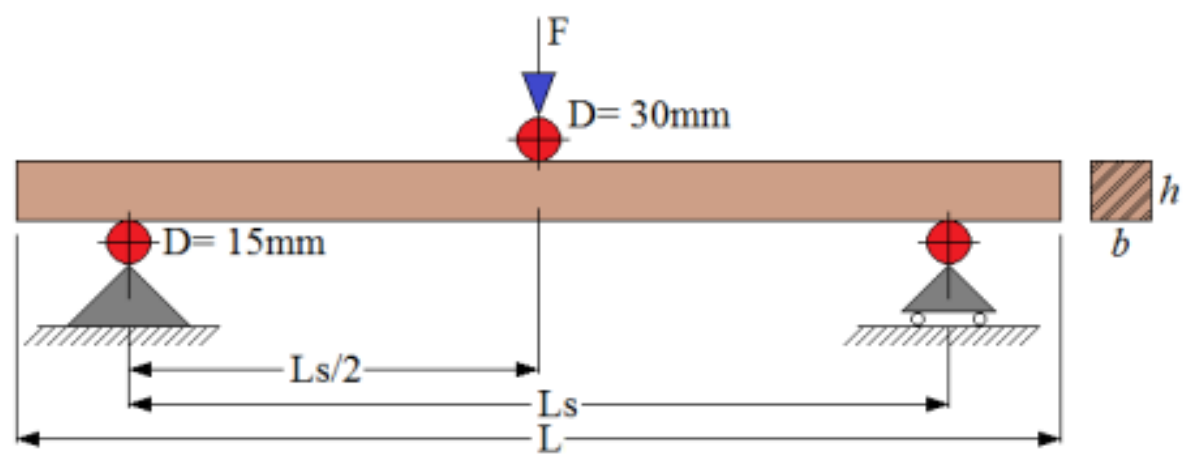

Şekil 3. Eğilme direnci test düzeneği ve ölçüleri (Öztürk ve İmirzi, 2017)

\subsection{Istatistiksel Analiz}

Elde edilen veriler SPSS 22 programında normallik testine tabi tutulmuştur. Verilerdeki dağılım normal dağılıma uymadığından kutu grafiği yöntemi ile uç değer çıkartma işlemi uygulanarak normal dağılım ve varyans homojenliği şartları sağlanmıştır. Değişkenlere ait ortalamalar arasındaki farklılıkların analizinde ANOVA testi uygulanmıştır.

\section{Bulgular ve Tartışma}

Eğilme testi sonrası deney örneklerinde meydana gelen deformasyonlar şekil 4’ de verilmiştir.

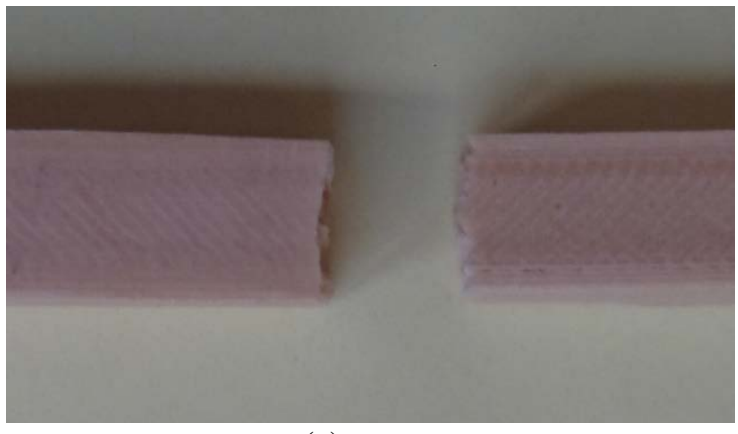

(a)

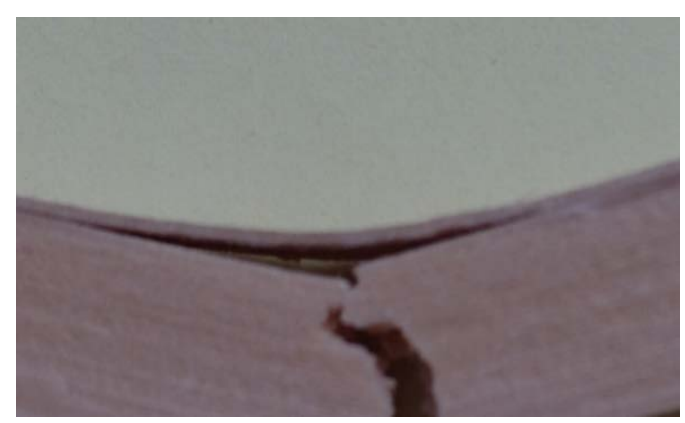

(b)

Şekil 4. Eğilme deneyi sonrası kaplamasız (a) ve kaplamalı (b) deney örneklerinde meydana gelen deformasyonlar.

Kaplama ile lamine edilmemiş kontrol gruplarında meydana gelen kırılma hattı (şekil 4.a) nispeten doğrusal iken kaplamalı deney örneklerindeki kırılma hattı (şekil 4.b) düzensizlik göstermekte ve kırılma hattı yüzey alanı 
artmaktadır. Bu düzensizliğin yüzeylere yapıştırılan kaplamaların yükleme ile ortaya konan kuvvete tepki vermesinden kaynaklandığı düşünülmektedir.

Alt ve üst katmanlarda kullanılan kaplamaların ağaç türüne göre lamine 3D malzemenin eğilme direnci ile ilgili bazı istatistiksel değerler Tablo2’ de verilmiştir.

Tablo 2. Eğilme direnci değerlerine ilişkin bulgular

\begin{tabular}{lccc}
\hline & \multicolumn{2}{c}{ Ĕ̆ilme Direnci Değerleri (MPa) } \\
\hline & $\begin{array}{c}\text { Kontrol grubu } \\
\text { deney örnekleri }\end{array}$ & $\begin{array}{c}\text { Kayın Kaplama ile lamine } \\
\text { edilmiş deney örnekleri }\end{array}$ & $\begin{array}{c}\text { Ihlamur Kaplama ile } \\
\text { lamine edilmiş deney } \\
\text { örnekleri }\end{array}$ \\
\hline Minimum & 35,09 & 34,63 & 34,64 \\
\hline Maksimum & 40,54 & 53,69 & 67,09 \\
\hline Ortalama & 37,00 & 46,41 & 44,46 \\
\hline Standart sapma & 1,69 & 5,88 & 10,53 \\
\hline Varyasyon katsayısı & 4,56 & 12,67 & 23,69 \\
\hline
\end{tabular}

Veriler arasında anlamlı bir farklılık olup olmadığının tespit edilmesi için ANOVA testi yapılmış ve sonuçlar Tablo 3' te verilmiştir.

Tablo 3. Grup ortalamaları arası farklılık analizi

\begin{tabular}{lccccc}
\hline \multicolumn{5}{c}{ Grup ortalamaları arası farklılık analizine ilişkin ANOVA Testi } \\
\hline & $\begin{array}{c}\text { Kareler } \\
\text { Toplamı }\end{array}$ & $\begin{array}{c}\text { Serbestlik } \\
\text { Derecesi }\end{array}$ & $\begin{array}{c}\text { Kareler } \\
\text { Ortalamas }\end{array}$ & $\mathrm{F}$ & $\begin{array}{c}\text { Sig. (p*) } \\
\text { (Anlamlılık) }\end{array}$ \\
\hline Gruplar arası & 276,96 & 2 & 138,48 & 7,03 & 0,01 \\
\hline Gruplar içi & 275,98 & 14 & 19,74 & \\
\hline Toplam & 552,94 & 16 & & & \\
\hline $\mathrm{p}^{*} \leq 0,05$ & & & &
\end{tabular}

Anova testi sonuçlarına göre gruplar arasında anlamlı bir farklılık olduğu belirlenmiştir $(\mathrm{p} \leq 0,05)$. Farklılığın hangi değişkenler arasında olduğunun belirlenmesi amacıyla yapılan Duncan testi sonuçları Tablo 4' te verilmiştir.

Tablo 4. DUNCAN Testi

\begin{tabular}{|c|c|c|c|}
\hline \multirow{3}{*}{ Kaplama Durumu } & \multicolumn{3}{|c|}{ Eğilme Direnci Değerleri (MPa) } \\
\hline & \multirow{2}{*}{$\mathrm{N}$} & \multicolumn{2}{|c|}{ Alfa için alt küme $=0,05$} \\
\hline & & 1 & 2 \\
\hline $\begin{array}{l}\text { Kaplamasız 3D } \\
\text { Malzeme (Kontrol) }\end{array}$ & 6 & 37,00 & \\
\hline Ihlamur Kaplamalı & 5 & 39,94 & \\
\hline Kayın kaplamalı & 6 & & 46,41 \\
\hline Sig. & & 0,286 & 1 \\
\hline
\end{tabular}

Tablo 4’te görüldüğü gibi 3D malzemenin kayın kaplama ile laminasyonu eğilme dayanımı artışında etkili olmuştur. Ihlamur kaplama ile laminasyonun ise eğilme direncine etkisi olmamıştır. Buna göre; en yüksek eğilme dayanımı 46,41 MPa ile kayın kaplama ile lamine edilmiş 3D malzemede elde edilirken, bunu 39,94 MPa ve 37,00 MPa ile aralarında fark önemsiz olmak üzere sırasıyla ıhlamur kaplama ile lamine edilmiş 3D malzeme ve laminasyonsuz 3D malzeme takip etmiştir. 3D malzemenin kayın kaplama ile laminasyonunun ihlamur kaplama ile laminasyonuna kıyasla daha yüksek eğilme direnci vermesinin kayın ağacının yoğunluğunun ıhlamur ağacına kıyasla daha yüksek olmasından kaynaklandığı düşünülmektedir. Ahşap malzemede yoğunluk arttıkça boşluk oranının azalıp yapısal madde oranının arttığ 1 ve böylelikle mekanik özelliklerin genellikle arttığı iyi bilinen bir gerçektir.

3 boyutlu yazıcı ile yazdırılan malzemelerin ahşap laminasyonu ile ilgili literatürde herhangi bir çalışmaya rastlanılmamıştır. Bu nedenle sonuçların benzer çalışmalarla karşılaştırılması mümkün olmamıştır. Ancak ahşap 
laminasyonu üzerine yapılan çalışmalara göre, ağaç türü, lamine ahşabın direnç değerlerine etki eden faktörlerin başında gelmektedir. Yoğunluk değeri daha yüksek olan kayın ağacı ile lamine edilmiş malzemenin eğilme direncinin daha yüksek olması literatür ile de uyum göstermektedir. 3D malzemenin laminasyonunda da benzer faktörlerin lamine 3D malzemenin direnç özellikleri üzerinde etkili olacağı düşünülmektedir.

Laminasyon işleminde, katmanlarda farklı malzemeler kullanılarak daha yüksek direnç özelliklerine sahip yeni malzemeler elde edilebilmektedir ( Li vd. 2017; Somireddy vd. 2019; Ferreira vd 2017; Christiyan vd 2016). Bu çalışmada da ara katman olarak ahşap katkılı filamentlerden üretilmiş 3D malzeme ve yüzeylerde de ahşap kaplama kullanılarak malzeme farklılaştırması yapılmıştır. Bu yapı ile kaplamalar dışında, ara katmanın dayanımının arttrılması ile elde edilen lamine malzemenin dayanımı da arttırılabilir. Yazıcının sistem özelliklerinden başlayarak yazdırma özelliklerine, yazıcıda kullanılan filamentin özelliklerine kadar pek çok faktör 3 boyutlu yazıcılardan yazdırılan malzemelerin direnç özellikleri üzerinde etkilidir. Açık ve kapalı yazdırma sistemleri üzerine yapılan bir çalışma sonucunda kapalı sistemlerden elde edilen malzemenin çekme direncinin yüksek olmasına rağmen sertlik değerinin daha düşük olduğu görülmüştür (Evlen 2018). Doluluk oranı da yazdırmada direnç özellikleri üzerinde etkili bir faktördür. Yüksek doluluk oranları ile yazdırılan malzemelerin mukavemet değerlerinin düşük doluluk oranları ile yazdırılanlardan daha yüksek mukavemet değerleri gösterdiği belirlenmiştir (Kaygusuz ve Özerinç 2018). Çalışmada seçilen ve süre ile malzeme tasarrufu sağlamak amacıyla kullanılan \%50 doluluk oranının arttırılması durumunda direnç özelliklerinde de artış sağlanabilecektir.

\section{Sonuç ve Öneriler}

Bu çalışmada, ahşap katkılı filamentlerle 3D yazıcıda üretilmiş malzemenin, her iki yüzeyine ahşap kaplama yapıştırmanın, elde edilen lamine malzemenin eğilme direncine etkisinin belirlenmesi amaçlanmıştır. Çalışma, ahşap katkılı veya katkısız filamentlerle 3D yazıcıda üretilen malzemelerin direnç değerlerinin ahşap kaplama laminasyonu ile arttrrılabileceğini göstermektedir. Dayanımın arttırlabilmesi için yoğunluğu daha yüksek ağaçlardan elde edilen kaplamaların kullanılması, kaplama kalınlıklarının arttııılması, kaplama kalitesinin arttırılması ve tutkal türünün değiştirilmesi ile 3D malzemenin eğilme direnci önemli derecede arttırılabilir. Ağaç malzemenin yanında 3D yazıcı ile elde edilen malzemenin yazdırılması esnasında kullanılan parametrelerin değiştirilmesi de mukavemetin artı̧ında bir etken olabilecektir. Açık yerine kapalı sistem kullanımı, doluluk oranının arttırılması, yazdırma yönü ve tipinin değiş̧tirilmesi ile ara katman güçlendirilebilecektir. Böylece güçlü bir ara katmanla birleşen yüksek özellikli ağaç malzeme ile lamine edilmiş malzemenin de direnç özellikleri arttırılabilecektir. Ayrıca ahşap kaplamalar ile lamine edilmiş malzeme, ahşap görüntüsü kazanarak malzemenin daha estetik görünmesine neden olmaktadır. Estetiğin önemli bir ürün tasarımı parametresi olduğu düşünülürse, ahşap kaplamalar ile 3D malzemelerin laminasyonunun önemi daha iyi anlaşılmış olacaktır. Elde edilen lamine malzemeler kutu mobilyalarda mobilya elemanı, lambri ve iç dekorasyonda çeşitli amaçlar için kullanılabilen malzemeler olabilecektir.

\section{Kaynaklar}

1. Aydin, A. , Kahraman, F., (2018). 3B Baskı teknolojisi kullanılarak hızlı prototipleme yapımı ve nesnelerin üretimi. Academic Perspective Procedia, 1 (1), 419-428.

2. Bhagia, S., Lowden, R. R., Erdman III, D., Rodriguez Jr, M., Haga, B. A., Solano, I. R. M., Ragauskas, A. J. (2020). Tensile properties of 3D-printed wood-filled PLA materials using poplar trees. Applied Materials Today, 21, 100832.

3. Burdurlu, M. Kılıç, A. C. İlce, Uzunkavak, O., (2007). The effects of ply organization and loading direction on bending strength and modulus of elasticity in laminated veneer lumber (LVL) obtained from beech (Fagus orientalis L.) and lombardy poplar (Populus nigra L.). Construction and Building Materials, 21(8), 1720-1725.

4. Chansoda, K., Suwanjamrat, C., Chookaew, W., (2020). Study on processability and mechanical properties of parawood-powder filled PLA for 3D printing material. The international Conference on Materials Research and innovation: IOP Conference Series Material Science and Engineering, 773.

5. Christiyan, K. J., Chandrasekhar, U., Venkateswarlu, K. (2016). A study on the influence of process parameters on the Mechanical Properties of 3D printed ABS composite. In IOP Conference Series: Materials Science and Engineering, Vol. 114, No. 1, p. 012109, Kuala Lumpur, Malaysia.

6. Evlen, H., Gülçin, E. R. E. L., Yılmaz, E. (2018). Açık ve kapalı sistemlerde doluluk oranının parça mukavemetine etkisinin incelenmesi. Politeknik Dergisi, 21(3), 651-662.

7. Ferreira, R. T. L., Amatte, I. C., Dutra, T. A., Bürger, D. (2017). Experimental characterization and micrography of 3D printed PLA and PLA reinforced with short carbon fibers. Composites Part B: Engineering, 124, 88-100.

8. Gedik, E., Togay, A. Coşkun, M., Demirhan, E.,(2018). Üç boyutlu baskının mobilya sektöründe ürün tasarımında kullanım imkânlarının araştırılması. International Journal of 3D Printing Technologies and Digital 
Industry, 2(2),16-25.

9. Grabowik, C., Kalinowski, K., Ćwikla, G., Paprocka, I., Kogut, P., (2017). Tensile tests of specimens made of selected group of the filament materials manufactured with FDM method. MATEC Web of Conferences 112 (21st Innovative Manufacturing Engineering \& Energy International Conference - IManE\&E 2017- May 2427), Iasi, Romania,

10. Guessasma, S., Belhabib, S., Nouri, H., (2019). Microstructure and mechanical performance of 3D printed wood-PLA/PHA using fused deposition modelling: Effect of printing temperature. Polymers (Basel),11, 1778.

11. He, M., Sun, X., Li, Z., Feng, W., (2020). Bending, shear, and compressive properties of three- and five-layer cross-laminated timber fabricated with black spruce. Journal of Wood Science, 66(38).

12. Kaboli, H. ., Clouston, P. L., (2019). Eastern Hemlock in Bamboo-Reinforced Glulam. Journal of Materials in Civil Engineering, 31(1).

13. Karaman, A., Yıldırım M.N., (2019). Cam elyaf kumaş ile desteklenmiş ahşap lamine malzemelerde eğilmede elastikiyet modülü. 4. Uluslararası Bilimsel ve Mesleki Çalışmalar Kongresi - Mühendislik. Kasım Ankara.

14. Kaygusuz, B., Özerinç, S., (2018). 3 boyutlu yazıcı ile üretilen PLA bazlı yapıların mekanik özelliklerinin incelenmesi. Makina Tasarım ve Imalat Dergisi, 16(1), 1-6.

15. Keskin, H., (2003). Lamine edilmiş Doğu Ladini (Picea orientalis Lipsky) odununun bazı fiziksel ve mekanik özellikleri. Süleyman Demirel Üniversitesi Orman Fakültesi Dergisi, A(1), 139-151.

16. Li, T., \& Wang, L. (2017). Bending behavior of sandwich composite structures with tunable 3D-printed core materials. Composite Structures, 175, 46-57.

17. Liu, L., Lin, M., Xu, Z., Lin, M., (2019). Polylactic acid-based wood-plastic 3D printing composite and

18. Nguyen, H. H., McGavin, R. L., Gilbert, B. P., Bailleres, H., (2019). Key mechanical properties of crossbanded laminated veneer lumbers manufactured from blending spotted gum and hoop pine veneers. BioResources, 14(4), 9117-9131.

19. Osmannezhad, S., Faezipour, M., Ebrahimi, G. (2013). Effects of GFRP on bending strength of glulam made of poplar (Populus deltoids) and beech (Fagus orientalis). Construction and Building Materials, 51, 34-39.

20. Petchwattana, N., Channuan, W., Naknaen, P., Narupai, B., (2019). 3D printing filaments prepared from modified poly(lactic acid)/teak wood flour composites: An investigation on the particle size effects and silane coupling agent compatibilisation. Journal of Physical Science, 30(2), 169-188.

21. Shin, Y. J., Yun, H. J., Lee, E. J., Chung, W. Y., (2018). A study on the development of bamboo/PLA biocomposites for 3D printer filament. Journal of Korean Wood Science Technology, 46 (1),107-113.

22. Somireddy, M., Singh, C. V., Czekanski, A. (2019). Analysis of the material behavior of 3D printed laminates via FFF. Experimental Mechanics, 59(6), 871-881.

23. T. S. E. (2014). TS EN 408 + A1 Ahşap yapılar - Yapı kerestesi ve yapıştırılmış lamine kereste - Bazı fiziksel ve mekanik özelliklerinin tayini, Türk Standardları Enstitüsü.

24. URL 1 1989: Available: http://www.intechopen.com/books/trends-in-telecommunications-technologies/gpstotal-electron-content-tec- prediction-at-ionosphere-layer-over-the-equatorial-region\%0AInTec. Yadina Abdullah1, 2 and Mahamod Ismail1 et al., "We are IntechOpen , the world 's leading publisher of Open Access books Built by scientists , for scientists TOP $1 \%$,” Intech, vol. 32, pp. 137-144, 1989, [Online].

25. Wang, X., Wu, Y., Chen, H., Zhou, X., Zhang, Z., Xu, W., (2019). Effect of surface carbonization on mechanical properties of LVL. BioResources, 1411,453-463.

26. Winter et al., (2018). Residual wood polymers facilitate compounding of microfibrillated cellulose with poly(lactic acid) for 3D printer filaments. Philosophical Transactions a of the Royal Society Mathematical Physical and Engineering Sciences,2112, 376, 2112.

27. Yıldırım, M..N., Karaman, A., (2019). 3d yazıcıda üretilmiş ' $T$ ' tipi bağlantı elemanlarının mobilya köşe birleştirmelerinde kullanımı. International Symposium on Multidisciplinary Studies and Innovative Technologies (ISMSIT-11-13 Kasım), 169-173, Ankara, Turkiye.

28. Yıldırım, M.N., Doruk, Ş., Karaman, A., (2019). 3d yazıcıda üretilmiş kavela bağlantı elemanının L tipi mobilya köşe birleştirmelerinde kullanımı. International Symposium on Multidisciplinary Studies and Innovative Technologies (ISMSIT-11-13 Kasım), 174-177, Ankara, Türkiye.

29. Zondi, M., D., Jarez-Mesa, R., Lluma-Fuentes, J., Roa, J.J., Travieso-Rodriguez, J., A., (2020). Experimental analysis of manufacturing parameters' effect on the flexural properties of wood-PLA composite parts built through FFF. The International Journal of Advanced Manufacturing Technology, 106, 3985-3998. 